University of Nebraska - Lincoln

DigitalCommons@University of Nebraska - Lincoln

Educational Psychology Papers and

Publications

Educational Psychology, Department of

$11-2008$

\title{
Mixed Methods Approaches in Family Science Research
}

Vicki L. Plano Clark

University of Nebraska-Lincoln, vicki.planoclark@uc.edu

Catherine Huddleston-Casas

University of Nebraska-Lincoln, chuddleston-casas2@unl.edu

Susan Churchill

University of Nebraska-Lincoln, schurchill2@unl.edu

Denise O'Neil Green

Central Michigan University

Amanda Garrett

University of Nebraska-Lincoln

Follow this and additional works at: https://digitalcommons.unl.edu/edpsychpapers

Part of the Educational Psychology Commons

Plano Clark, Vicki L.; Huddleston-Casas, Catherine; Churchill, Susan; O'Neil Green, Denise; and Garrett, Amanda, "Mixed Methods Approaches in Family Science Research" (2008). Educational Psychology Papers and Publications. 81.

https://digitalcommons.unl.edu/edpsychpapers/81

This Article is brought to you for free and open access by the Educational Psychology, Department of at DigitalCommons@University of Nebraska - Lincoln. It has been accepted for inclusion in Educational Psychology Papers and Publications by an authorized administrator of DigitalCommons@University of Nebraska - Lincoln. 


\title{
Mixed Methods Approaches in Family Science Research
}

\author{
Vicki L. Plano Clark \\ University of Nebraska-Lincoln
}

Catherine A. Huddleston-Casas

University of Nebraska-Lincoln (Omaha Campus)

Susan L. Churchill

University of Nebraska-Lincoln

\section{Denise O'Neil Green}

Central Michigan University, Mt. Pleasant

\author{
Amanda L. Garrett \\ University of Nebraska-Lincoln
}

\begin{abstract}
The complex phenomena of interest to family scientists require the use of quantitative and qualitative approaches. Researchers across the social sciences are now turning to mixed methods designs that combine these two approaches. Mixed methods research has great promise for addressing family science topics, but only if researchers understand the design options and procedures that accompany this methodological choice. Discussions of mixed methods in the family science literature are difficult to locate, and little has been written about how family scientists apply this approach in practice. This article presents an overview of mixed methods research, including its definition, terminology, and design types, and examines how it is being successfully used and reported in family research journals. The authors review the application of mixed methods designs in 19 studies and discuss design features and issues that arose during implementation. They conclude with recommendations for family scientists considering using this approach.
\end{abstract}

Keywords: mixed methods research; research methods; family research; quantitative research; qualitative research

The authors are grateful to John W. Creswell for his careful review and comments on a draft of this article and for the constructive comments from an anonymous reviewer. Correspondence: Vicki L. Plano Clark, 114 Teachers College Hall, University of Nebraska-Lincoln, Lincoln, NE 68588-0345; email vpc@unlserve.unl.edu . 
$\mathrm{F}$ amily scientists conduct research in order to describe and explain the inherent complexity of families. The prevailing theoretical perspectives employed by family scientists are systemic, emphasizing both process and context. Addressing such complexity requires research that is "multidisciplinary, broad in scope, and linked to the contexts in which people live" (O'Brien, 2005, p. 881). In a recent critique of the field, $\mathrm{O}^{\prime}$ Brien concluded that there are inconsistencies between family scientists' theoretical assumptions and both the design of their studies and the analytic methods used, and she suggested that family scientists expand the range of analytic possibilities by using multiple methods, measures, and participants in their research.

The ability of family scientists to study complex phenomena is restricted when they limit themselves to one type of research methodology, such as quantitative or qualitative research. More than a decade ago, Mangen (1995) observed a tendency among scholars to "adopt an ideological adherence to certain research methods and techniques of analysis that may not necessarily converge with, or extend the theories they are investigating" (p. 149). About the same time, Handel (1996) reported a concern that research in the field was being driven by methods rather than questions that merit attention and asserted that questions should have priority and the methods adopted should be appropriate for those questions. Similarly, Hendrickson Christensen and Dahl (1997) asserted that dichotomous thinking regarding research methods was leading to a construction of hierarchies of methods that was limiting both the kinds of questions that could be asked and the kinds of answers that could be found. These challenges to the adequacy of one approach are not new. In 1927, Burgess argued for "equal recognition" of qualitative and quantitative approaches, describing them as "mutually complementary."

In addition to the calls for family scientists to be open to the use of different methods, a handful of scholars have encouraged family scientists to combine quantitative and qualitative methods within their research studies. Scholars arguing for mixing methods cite that the separate strengths and weaknesses of quantitative and qualitative approaches complement one another, making them suitable for use together (Brewer \& Hunter, 1989; Hendrickson Christensen \& Dahl, 1997; Mangen, 1995; Rank, 1996). Another reason cited for mixing methods is to enhance the validity of findings by obtaining similar results from each method employed (Greene, 2005; Perlesz \& Lindsay, 2003; Rank, 1996). Scholars also assert that mixing methods allows researchers to challenge conventional wisdom by uncovering dissonant data and confronting discrepancies (Greene, 2005; Perlesz \& Lind- 
say, 2003; Rank, 1996) and to better understand diverse family forms (Greenstein, 2006).

Despite the growing arguments for combining quantitative and qualitative methods, family scientists' current use of mixed methods research is limited (Greenstein, 2006). This may be due in part to most family scientists having limited exposure to and knowledge about this approach. Few graduate programs offer a course in conducting mixed methods research (Creswell, Tashakkori, Jensen, \& Shapley, 2003), and most researchers are trained in quantitative or qualitative approaches, not both. The problem of the lack of formal coursework is compounded by the fact that literature discussing the use of mixed methods in family science is not easy to find, in part due to a lack of a common definition of mixed methods and language for discussing this approach. Whereas methodologists have adopted the term mixed methods research to describe approaches that combine quantitative and qualitative research (Tashakkori \& Teddlie, 2003), the family science literature includes references to blending methods (Rank, 1988), combining methods (Rank, 1996), multimethod research (Brewer \& Hunter, 1989), and consolidation (Mangen, 1995). In addition, the use of mixed methods research may be limited because it presents family science researchers with numerous logistical challenges such as requiring extensive time and effort to implement the two methods, working in teams where members have diverse methodological training, and getting research using this approach successfully reviewed and published (Plano Clark, 2005; Sandelowski, 2003; Shulha \& Wilson, 2003).

With the emerging importance of mixed methods research across the social sciences (Tashakkori \& Teddlie, 2003) and its appropriateness for many family science questions, family scholars must be able to assess when it is the appropriate design choice, anticipate challenges associated with this choice, and critically evaluate its application. Therefore, the purpose of this article is to present an overview of mixed methods research, including its definition, terminology, and design types, and to examine how mixed methods is being successfully applied and reported in mainstream family research journals. This article is relevant for family scholars who desire a better understanding of mixed methods and want models of how other family scholars effectively apply this approach in their own research. Methodologists and researchers interested in mixed methods research will benefit from knowing how the discipline of family science has adapted mixed methods approaches to its research questions and the challenges that arise from using this approach within the family science context. 


\section{Defining Mixed Methods Research}

This examination of family scientists' use of mixed methods research is informed by the larger mixed methods literature. Broadly speaking, mixed methods research refers to the combination of quantitative and qualitative research (Greene, Caracelli, \& Graham, 1989), and its basic premise is that the combination provides a better understanding of research problems than either approach by itself (Creswell, 2005). Creswell and Plano Clark (2007) suggest that this approach is both a methodology and a method. When considered as a methodology, authors tend to emphasize its philosophical foundations and the implications of those foundations (Tashakkori \& Teddlie, 1998). Although some consider mixed methods as untenable because it combines different worldviews (Sale, Lohfeld, \& Brazil, 2002; Smith \& Heshusius, 1986), today scholars note that worldviews such as pragmatism (Tashakkori \& Teddlie, 2003), a transformative-emancipatory perspective (Mertens, 2003), or a "dialectical perspective" of explicitly using both post- positivism and constructivism (Greene \& Caracelli, 1997) can provide a philosophical foundation for mixed methods research. Although philosophical foundations are one important aspect of mixed methods research, the focus of this article is on methods and how family science researchers actually combine qualitative and quantitative data in published studies. This focus means that we define mixed methods research as consisting of a set of designs and procedures in which both quantitative and qualitative data are collected, analyzed, and mixed in a single study or series of studies (Creswell \& Plano Clark, 2007).

\section{Locating and Reviewing Mixed Methods Studies in Family Science Research}

To examine the use of mixed methods within family science, we conducted a systematic review of recently published family science research articles. Because of the multidisciplinary nature of family science, research from the field is published in diverse outlets (such as nursing, child development, and sociology). We chose to identify a sample of mixed methods studies that self- identified as having combined quantitative and qualitative methods and had been successfully published in mainstream family science research journals. Consequently, we limited our review to articles appearing in four well-known family science research journals: Journal of Marriage and Family, Journal of Family Issues, Family Relations, and Family Process. We limited our sample to these journals because they are well respected in the family science discipline; are 
all published or sponsored by the National Council on Family Relations or the Family Issues Institute, leading family research professional organizations; and they represent both empirical and applied emphases. In addition, we limited our sample to articles that were published during the past 10 years (January 1996 to December 2005) based on the tradition of decade-based methodological reviews in the field (e.g., Coleman, 1995; Walker, 2005). Whereas these criteria were not expected to identify all examples of mixed methods research, they were specified to produce a sample of articles that will provide a meaningful picture of how mixed methods research is being applied within family research.

We searched article titles and abstracts of these journals using electronic databases (PsycINFO and Sociological Abstracts) to identify studies that made explicit use of mixed methods approaches. Because the term mixed methods does not frequently appear in the family science literature, we used the following terms and logic operators: mixed method* OR multimethod OR [(quantitative OR survey) AND (qualitative OR interview)]. These search terms have been successfully used for other disciplines (Creswell, Fetters, \& Ivankova, 2004; Hanson, Creswell, Plano Clark, Petska, \& Creswell, 2005; Plano Clark, 2005) and therefore also permit cross-disciplinary comparisons of the results and provide researchers with strategies to use in their own searches for exemplar articles. Each journal was searched using the two electronic databases, and a sample of issues was also examined by hand. Due to the nature of electronic searches, the search terms appeared in some articles even though they were not examples of mixed methods research (e.g., when a qualitative study mentioned that previous research on a topic had been limited to quantitative approaches). We therefore reviewed each identified article to determine whether it reported the collection and analysis of both quantitative and qualitative data. From this search of 2,142 articles, 49 articles satisfied the search criteria, and 19 articles met the definition of mixed methods research and were included in our sample.

We developed a coding scheme to guide our analysis of the mixed methods studies based on the mixed methods literature and practices used in previous disciplinary reviews of the use of mixed methods (Creswell et al., 2004; Hanson et al., 2005; Plano Clark, 2005). This analytic induction process (Punch, 1998) included identifying the quantitative and qualitative procedures used (e.g., participant sampling and how data were collected and analyzed), the authors' reasons for collecting both types of data, and the terminology used to convey the mixed nature of the study. To encourage the use of a common mixed methods language in family science, we applied Creswell and Plano Clark's 
(2007) mixed methods design framework to classify the type of mixed methods design, identify specific features related to how the mixed methods approach was applied, and develop a mixed methods research question that attempted to capture the study's overall intent. We also noted procedural issues that occurred during the implementation of the mixed methods approach and thematically analyzed these passages (Miles \& Huberman, 1994). Finally, we coded the topic of each study using the National Council on Family Relations Annual Conference (2006) subject code list.

Three of the coauthors with extensive training in coding qualitative data independently coded the 19 articles. The first author led the article coding and trained the other two coders in the mixed methods scheme that was developed. All codes were compared and discrepancies were discussed until 100\% agreement had been reached.

\section{The Use of Mixed Methods in Family Research}

Our review of the 19 mixed methods studies resulted in four categories of findings. First, we provide an overview of the articles as examples of family science research. Second, we introduce the different types of mixed methods designs and describe how they were used within the studies. Next, we present the important features of these mixed methods designs. Finally, we discuss the procedural issues that emerged from the studies' reports.

\section{Overview of the Family Research Studies Using Mixed Methods Research}

As a general overview of the articles, we noted the journals in which they were published, each author's country of affiliation, and the topics studied (see Table 1). We also examined the data collection and analysis procedures and the use of theory reported in the studies along with the terminology employed to convey the use of a mixed methods approach.

Mixed methods studies were located in all four family science journals reviewed in this study: Journal of Marriage and Family (3), Journal of Family Issues (8), Family Relations (5), and Family Process (3). Representation across the journals was relatively equal and low, with fewer than $1 \%$ of the manuscripts published during the stated time frame being identified as mixed methods (ranging from $0.3 \%$ of publications in Journal of Marriage and Family to $1.9 \%$ in Journal of Family Issues). Authors from both U.S. and international affiliations contributed these 
Table 1. Overview of the Family Science Mixed Methods Research Studies $(N=19)$

\begin{tabular}{|c|c|c|c|}
\hline Article & Journal & $\begin{array}{l}\text { Author } \\
\text { Affiliation }\end{array}$ & Topic of the Study ${ }^{a}$ \\
\hline $\begin{array}{l}\text { Campbell and Demi } \\
\text { (2000) }\end{array}$ & FR & United States & $\begin{array}{l}\text { War and families; family } \\
\text { stress and coping }\end{array}$ \\
\hline Carr (2005) & JMF & United States & Midlife issues, intergenerational issues \\
\hline Dalla and Gamble (1997) & ) FR & United States & Parenthood, adolescence, race/ethnicity \\
\hline $\begin{array}{l}\text { Gibson-Davis, Edin, and } \\
\text { McLanahan (2005) }\end{array}$ & $\mathrm{JMF}$ & United States & $\begin{array}{l}\text { Unmarried parents; socioeconomic } \\
\text { class and inequality }\end{array}$ \\
\hline $\begin{array}{l}\text { Gomel, Tinsley, Parke, } \\
\text { and Clark (1998) }\end{array}$ & JFI & United States & Family relationships, race/ethnicity \\
\hline $\begin{array}{l}\text { Javo, Alapack, } \\
\text { Heyerdahl, and } \\
\text { Ronning (2003) }\end{array}$ & $\mathrm{FP}$ & Norway & Ethnicity and families; parenthood \\
\hline $\begin{array}{l}\text { Katz and Lowenstein } \\
\text { (1999) }\end{array}$ & FR & Israel & $\begin{array}{l}\text { Immigration and migration; } \\
\text { intergenerational issues }\end{array}$ \\
\hline $\begin{array}{l}\text { Knodel and } \\
\text { Saengtienchai (2005) }\end{array}$ & JFI & United States & $\begin{array}{l}\text { Health, wellness, and illness; } \\
\text { international families }\end{array}$ \\
\hline $\begin{array}{l}\text { Lavee, Ben-David, and } \\
\text { Azaiza (1997) }\end{array}$ & $\mathrm{FP}$ & Israel & $\begin{array}{l}\text { Family stress and coping; cross-cultural } \\
\text { issues }\end{array}$ \\
\hline $\begin{array}{l}\text { Marshall and Solomon } \\
\text { (2004) }\end{array}$ & FP & United States & Mental health; therapy and counseling \\
\hline $\begin{array}{l}\text { Mason, Harrison-Jay, } \\
\text { Svare, and Wolfinger } \\
\quad(2002)\end{array}$ & JFI & United States & Remarriage, stepfamilies; parenthood \\
\hline $\begin{array}{l}\text { McGraw, Zvonkovic, } \\
\text { and Walker (2000) }\end{array}$ & JMF & United States & Work and families; ethics and values \\
\hline Miall and March (2005a) & FR & Canada & Fatherhood, adoption \\
\hline Miall and March (2005b) & ) JFI & Canada & Adoption, community, families \\
\hline $\begin{array}{l}\text { Richter (1997) } \\
\text { power }\end{array}$ & JFI & United States & Work and families; decision making and \\
\hline $\begin{array}{l}\text { Strazdins and Broom } \\
(2004)\end{array}$ & JFI & Australia & Gender and roles; mental health \\
\hline $\begin{array}{l}\text { Struthers and Bokemeier } \\
\text { (2000) }\end{array}$ & r JFI & United States & Rural and urban families; ethics and values \\
\hline $\begin{array}{l}\text { Weigel-Garrey, Cook, } \\
\text { and Brotherson (1998) }\end{array}$ & JFI & United States & Child development, disabilities \\
\hline Weine et al. (2005) & FR & United States & Refugees, interventions \\
\hline
\end{tabular}

FR = Family Relations; JMF = Journal of Marriage and Family; JFI = Journal of Family Issues; FP = Family Process.

a. Topics selected from the National Council on Family Relations Annual Conference (2006) Call for Papers subject code list.

mixed methods studies to these journals, and they implemented mixed methods research designs to study a wide range of family science topics, as noted in Table 1. 
Across the studies, there was little variation in the procedures used to collect and analyze quantitative and qualitative data. Quantitative data collection methods included cross-sectional and cohort surveys and structured interviews; analyses examined descriptive trends, sought to identify differences among groups, or related variables through regression-based analysis techniques. Qualitative data were gathered through interviews (one-on-one and focus group) and through open-ended questions. Thematic analysis was generally used to analyze the qualitative data. Illustrative quotes and descriptive examples were also gleaned. The role of theory varied among the selected studies. Some reported an explicit statement of a theory (such as social comparison theory or feminism) or at least a loose framework. Others had no clear discussion of theory utilization, and a few authors discussed the purposeful absence of theory to allow for theory generation during the mixed methods study.

The use of mixed methods terminology in these studies was very limited. The majority of studies used a combination of the words quantitative and qualitative $(n=13)$ when discussing each aspect of the study respectively. Three studies included the term multimethod, and only one study contained the term mixed methods. A few studies used phrases such as two stage or dual methodological strategies to convey the nature of the overall design.

\section{Mixed Methods Designs Used in the Studies}

We used Creswell and Plano Clark's (2007) four-design framework to guide our examination of the use of mixed methods research in family science. This framework is built from the mixed methods literature (Creswell, Plano Clark, Gutmann, \& Hanson, 2003; Greene et al., 1989; Morgan, 1998; Morse, 1991; Tashakkori \& Teddlie, 1998), is informed by how social science researchers actually apply these approaches in practice, and represents a parsimonious typology that is straightforward to apply. Its four major designs, triangulation, explanatory, exploratory, and embedded, are illustrated in Figure 1, and a brief introduction to each follows with specific examples drawn from the reviewed studies.

Studies using triangulation designs. The triangulation design is probably the oldest and most recognizable form of mixed methods research (Creswell, Plano Clark, et al., 2003; Jick, 1979). It is used for a variety of reasons centering on the need to bring together different but complementary kinds of data (Morse, 1991). Researchers using this approach directly compare quantitative and qualitative forms of evidence 
(a) Triangulation Design

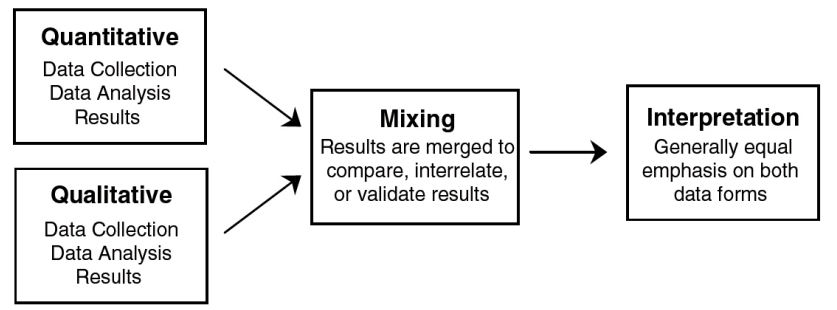

(b) Explanatory Design

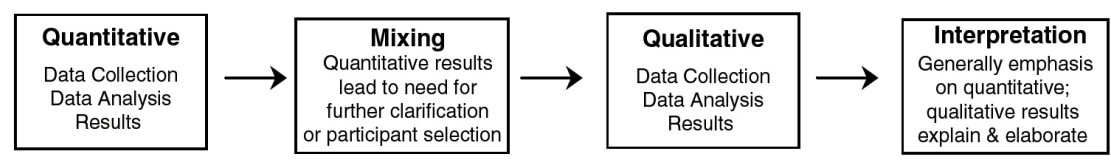

(c) Exploratory Design

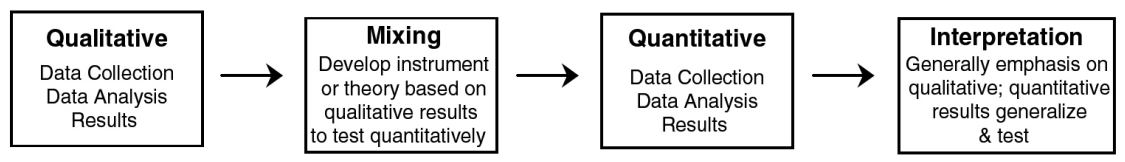

(d) Embedded Design ${ }^{a}$

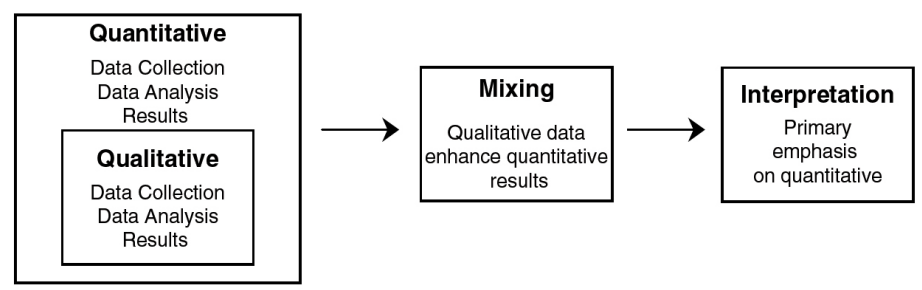

Figure 1. Four Major Mixed Methods Designs. This figure is based on Creswell and Plano Clark's (2007) discussion of mixed methods designs. (a. Embedded design could also have quantitative data embedded within a qualitative framework.)

to corroborate results or identify discrepancies between data sources or to use one form of evidence to expand on the results of the other. As depicted in Figure 1a, researchers using a triangulation design collect and analyze the quantitative and qualitative data in parallel. These two data sets are often collected at (roughly) the same time, but in some studies, researchers may analyze their own qualitative data in combination with secondary quantitative data such as from a national survey. After analyzing the data sets independently, the researcher attempts to merge them by comparing or synthesizing the separate results or 
by transforming one data type into the other type to facilitate relating the two data types. Typically, the quantitative and qualitative components of triangulation studies are emphasized equally in the study's conclusions.

We classified 11 studies (58\%) in our sample as having used a triangulation design (see Table 2). These studies focused on the hallmark of this design, merging quantitative and qualitative data. The reasons for combining methods in these studies included using one data set to confirm or give context to the results from the other data set and obtaining a more complete understanding of a complex topic by including multiple types of data. For example, Gomel, Tinsley, Parke, and Clark (1998) analyzed questionnaire and focus group data to study economic hardships on family relations. These authors explained how their two data forms were used to confirm, expand, and provide context. They described their data as tapping "different constructs" in order to achieve a "complementary picture" (p. 453). Gibson-Davis, Edin, and McLanahan (2005) expressed how two data sources, surveys and interviews, were utilized to provide perspective on the declining rate of marriage among low-income couples. The authors detail how discrepancies were explored through triangulation of the different data sets. Mason, Harrison-Jay, Svare, and Wolfinger (2002) described using in- depth interviews to support the results of a representative survey for understanding the perspectives of stepparents. Strazdins and Broom (2004) gleaned direct quotations from open-ended survey questions to provide a contextual background for their quantitative findings in their study of emotional work and psychological stress among women.

Studies using explanatory designs. The explanatory design is used when a researcher needs qualitative data to expand on or explain initial quantitative findings (Morse, 1991). It can also be used when quantitative findings are needed to direct the selection of participants for a qualitative investigation (Morgan, 1998). That is, in the explanatory design, the qualitative data collection emerges from and is linked to the quantitative results. Studies using the explanatory design take place in two sequential phases, with the quantitative data collection and analysis occurring first and usually providing the overall emphasis of the study (Creswell, Plano Clark, et al., 2003). Figure 1b illustrates how the qualitative data from the second phase are connected to and follow up on the findings of the first quantitative phase.

Five of the studies (26\%) we examined utilized qualitative data to expand on and explain initial quantitative results in explanatory designs (see Table 2). For example, Weine et al. (2005) studied refugee families' 
Table 2. Mixed Methods Design Types and Features

\begin{tabular}{|c|c|c|}
\hline $\begin{array}{l}\text { Mixed Methods Design Type } \\
\text { (timing, mixing) }^{\mathrm{b}}\end{array}$ & Article & Weighting ${ }^{c}$ \\
\hline \multirow{11}{*}{$\begin{array}{l}\text { Triangulation } \\
\quad \text { (concurrent, merged) }\end{array}$} & Campbell and Demi (2000) & Unequal: quantitative \\
\hline & Carr (2005) & Equal \\
\hline & $\begin{array}{l}\text { Gibson-Davis, Edin, and } \\
\text { McLanahan (2005) }\end{array}$ & Unequal: qualitative \\
\hline & $\begin{array}{l}\text { Gomel, Tinsley, Parke, and } \\
\text { Clark (1998) }\end{array}$ & Unequal: quantitative \\
\hline & Katz and Lowenstein (1999) & Unequal: quantitative \\
\hline & $\begin{array}{l}\text { Knodel and Saengtienchai } \\
\text { (2005) }\end{array}$ & Equal \\
\hline & $\begin{array}{l}\text { Lavee, Ben-David, and } \\
\text { Azaiza (1997) }\end{array}$ & Unequal: quantitative \\
\hline & $\begin{array}{l}\text { Mason, Harrison-Jay, Svare, } \\
\text { and Wolfinger (2002) }\end{array}$ & Equal \\
\hline & Strazdins and Broom (2004) & Unequal: quantitative \\
\hline & $\begin{array}{l}\text { Struthers and Bokemeier } \\
(2000)\end{array}$ & Unequal: qualitative \\
\hline & $\begin{array}{l}\text { Weigel-Garrey, Cook, and } \\
\text { Brotherson (1998) }\end{array}$ & Equal \\
\hline \multirow{5}{*}{$\begin{array}{l}\text { Explanatory } \\
\text { (sequential: quantitative } \\
\text { first, connected) }\end{array}$} & Dalla and Gamble (1997) & Equal \\
\hline & $\begin{array}{l}\text { Javo, Alapack, Heyerdahl, } \\
\text { and Ronning (2003) }\end{array}$ & Unequal: quantitative \\
\hline & $\begin{array}{l}\text { Marshall and Solomon } \\
\text { (2004) }\end{array}$ & Unequal: quantitative \\
\hline & $\begin{array}{l}\text { McGraw, Zvonkovic, and } \\
\text { Walker (2000) }\end{array}$ & Unequal: qualitative \\
\hline & Weine et al. (2005) & Unequal: quantitative \\
\hline \multirow{3}{*}{$\begin{array}{l}\text { Exploratory } \\
\text { (sequential: quantitative } \\
\text { first, connected) }\end{array}$} & Miall and March (2005a) & Unequal: qualitative \\
\hline & Miall and March (2005b) & Equal \\
\hline & Richter (1997) & Equal \\
\hline
\end{tabular}

a. Mixed methods design types from Creswell and Plano Clark's (2007) typology.

b. Timing is the temporal relationship between when the quantitative and qualitative data are used in the study. Mixing is the primary way in which the quantitative and qualitative data and results are related to each other within the study.

c. Weighting is the relative emphasis of the quantitative and qualitative data in addressing the study's purpose. 
engagement in multiple family group interventions. They first identified quantitative predictors of engagement and then collected qualitative family interviews "to better understand the processes by which families experience engagement" (p. 560). McGraw, Zvonkovic, and Walker (2000) moved to an explanatory design to explain questions that emerged about women's lived experience of participating in the initial quantitative phase of their research on work and family processes. The qualitative phase of this study connected to and built on the findings of the first phase, and participants for the in-depth interviews were selected from respondents to the first quantitative survey stage.

Studies using exploratory designs. The third mixed methods design type is the exploratory design. This design is best suited when there is little empirical knowledge about a particular research area (i.e., lack of a theoretical framework, instruments, or variables; Creswell \& Plano Clark, 2007). Researchers choose to use an exploratory design when they need to first explore a phenomenon qualitatively before they can measure or test it (Creswell, Plano Clark, et al., 2003; Morgan, 1998). This design is often used when developing an instrument and is an essential aspect of the overall study (Creswell, 1999; Creswell et al., 2004). As shown in Figure 1c, exploratory designs begin with a qualitative, in-depth exploration and then build to a secondary quantitative phase that is connected to the initial qualitative results.

Three examples $(16 \%)$ of exploratory designs were represented in the sample studies where the researchers needed qualitative information about a topic before attempting to measure related constructs or when they wanted to establish the generalizability of their qualitative results (see Table 2). Miall and March (2005a) focused on gathering data and generating hypotheses rather than testing them. These authors highlighted the value of exploratory qualitative interviews in their research on adoption and birth fathers, as they used qualitatively derived themes to compose a questionnaire that was subsequently implemented. Similarly, Richter (1997) used qualitative data from one-on-one and focus group interviews to develop a model of the childcare decision- making process for urban Thai women. She then followed up with quantitative data to test this model using a nationally representative sample.

Studies using embedded designs. The final design discussed in the Creswell and Plano Clark (2007) typology is the embedded design. In an embedded design, the researcher uses one type of data in a supportive role to the other method type. A distinctive element of an embedded design is that the overall study is guided by a traditional quantita- 
tive or qualitative methodology (such as an experiment or case study) that frames the overall emphasis and direction of the study (Greene \& Caracelli, 1997). The supplemental data set is collected to enhance the overall study, and it can be collected before, during, or after the collection and analysis of the emphasized data (Creswell \& Plano Clark, 2007). This embedded relationship is depicted in Figure 1d for a study in which qualitative data are collected to enhance a largely quantitative study. The two forms of data are employed to address different aspects of the research (such as measuring outcomes and describing process in an experiment), not to compare and contrast one with the other as in the triangulation design (Creswell, Plano Clark, et al., 2003). Although this design represents a common approach in some fields, such as the health sciences (Creswell, Fetters, Plano Clark, \& Morales, in press), we did not identify any examples of studies using embedded designs in family research.

\section{The Mixed Methods Design Features}

Implicit to the four major mixed methods designs are important features about which the researchers make decisions during implementation. Specifically, the designs are distinguished by the timing, weighting, and mixing of the quantitative and qualitative elements (Creswell \& Plano Clark, 2007). These features and their applications within the studies are summarized in Table 2 and discussed below.

Timing in the mixed methods studies. Mixed methods researchers need to decide when the quantitative and qualitative methods will be implemented relative to each other (Greene et al., 1989). Timing in mixed methods studies refers to not only when the data are collected but, more important, to when the data are analyzed and interpreted (Morgan, 1998). There are two options for the timing within mixed methods studies: concurrent and sequential (Morse, 1991). Concurrent studies are conducted with the quantitative and qualitative elements implemented in one phase at roughly the same time (see Figure 1a). Sequential studies involve a definite sequence between the two types of methods (see Figures $1 \mathrm{~b}$ and 1c). In this sample, researchers' decisions about timing were generally straightforward to identify because they relate to typically reported procedures of how data were collected and analyzed. Authors indicated nearly equal use of the two timing approaches, concurrent $(n=11)$ and sequential $(n=8)$. Of the sequential designs, 5 studies reported using quantitative data and results first, and 3 reported starting with qualitative data and results. 
Weighting in mixed methods studies. Mixed methods researchers should consider the weighting of their studies in addition to their timing. Weighting is the relative importance of the quantitative and qualitative methods for addressing a study's purpose (Morgan, 1998), and as such, typical weightings are indicated in the "Interpretation" boxes of Figure 1. Mixed methods studies have either an equal or an unequal weight, depending on the research questions and philosophical assumptions behind the study (Morgan, 1998; Morse, 1991). Equally balanced studies place relatively equal emphasis on both the quantitative and qualitative aspects (see Figure 1a); studies with an unequal balance may prioritize either the quantitative or qualitative aspects (see Figures $1 b, 1 c$, and $1 d)$.

Compared to classifying timing, categorizing the studies' weighting was more difficult and subjective. Few studies gave explicit statements indicating how the authors' perceived the relative importance of the two methods for meeting the studies' objectives. Some indicated their priority with statements such as "in the primary quantitative study" (Javo, Alapack, Heyerdahl, \& Ronning, 2003, p. 151) and "the main concern of the study was ..." (Weine et al., 2005, p. 563). When not explicitly indicated, we based our classifications on the stated purpose, the use of a specific world- view, the relative sophistication and/or thoroughness of the two approaches, and the amount of attention paid to the two approaches in the article (Creswell \& Plano Clark, 2007). Our classifications of the studies' weighting found that 12 studies used an unequal weighting (8 prioritized the quantitative, and 4 prioritized the qualitative), whereas 7 studies weighted the two methods equally. The weighting also varied within the design types, as indicated in Table 2.

Mixing in mixed methods studies. Finally, deciding how one will mix the quantitative and qualitative aspects of a study is essential for mixed methods research. Mixing refers to how the quantitative data and results are related to the qualitative data and results, and it aims to produce understandings that go beyond simply what is learned from the separate components of the study ( $\mathrm{O}^{\prime}$ Cathain, Murphy, \& Nicholl, 2007). At a conceptual level, mixing generally occurs in one of three ways: the two data sets are merged, connected, or embedded (Creswell \& Plano Clark, 2007). Merged studies attempt to fully integrate the two data sets either during data analysis (such as when one type of data is transformed into the other data type) or during the final interpretation and discussion (see "Mixing" box of Figure 1a). Connected studies link one type of data to the results of the other type. As shown in Figures $1 \mathrm{~b}$ and 1c, the initial results are in some way inadequate and call for the 
other data type to build on or follow up the initial results in studies, using a connected approach. Embedded studies use one type of data within the context of a design based on the other data type (see "Mixing" box of Figure 1d). Thus, embedded mixing occurs at the design level, not just at the data level (Greene \& Caracelli, 1997). To highlight the importance of mixing within mixed methods studies, Creswell and Plano Clark suggest that researchers develop mixed methods research questions to guide the mixing procedures and make them explicit. To date, few examples of such questions exist in the literature.

The primary ways that the authors mixed the quantitative and qualitative data varied among the studies, and along with timing, mixing was instrumental in classifying the design used. Eleven studies merged their data sets. This was accomplished by comparing separate results to see if they corroborated each other (e.g., Weigel-Garrey, Cook, \& Brotherson, 1998), using qualitative quotations and findings to illustrate quantitative results (e.g., Katz \& Lowenstein, 1999), and transforming qualitative findings into quantitative counts to facilitate relating the two databases (e.g., Lavee, Ben- David, \& Azaiza, 1997). The remaining 8 studies mixed by connecting the two data sets. When quantitative data were analyzed first, authors connected to the qualitative phase by developing interview questions that followed up on significant quantitative results (e.g., Javo et al., 2003) and by deciding how to select participants for the second phase (e.g., McGraw et al., 2000). When qualitative data were analyzed first, authors connected by developing a questionnaire based on qualitative findings (Miall \& March, 2005a) and by identifying variables to be tested from a qualitative model (Richter, 1997). As previously noted in regard to embedded designs, none of the studies we examined mixed at the design level by embedding one type of data within a larger design of the other type.

\section{Procedural Issues With Mixing Quantitative and Qualitative Data in the Studies}

We wanted to examine the procedural issues that emerged during these studies in addition to classifying the types of designs used. Researchers can learn about the types of issues to anticipate by examining the experiences of other researchers. Therefore, as we analyzed the designs and features of these studies, we also asked, What kinds of procedural issues did the researchers mention in relation to their use of mixed methods approaches for their studies? These issues were thematically analyzed, and three categories emerged: sampling decisions, procedures for mixing the two datasets, and logistical challenges. 
The researchers made decisions about how to select the samples for the quantitative and qualitative data collection. Five studies used the same sample size and the same individuals for both data collections. The other 14 studies used a smaller sample for the qualitative data collection and a larger sample for the quantitative data collection. Of these, 7 used completely different individuals for the two samples, and 7 studies used a subset of the quantitative sample for the qualitative data collection. Consistent with Creswell and Plano Clark's (2007) recommendations, all studies classified as using an exploratory design used different samples for the two phases, and all but 1 of the explanatory examples used a subset of the quantitative sample for the qualitative sample in the second phase. Studies using a triangulation design made use of all of these sampling strategies ( 5 used identical samples, 3 had one sample as a subset of the other, and 3 used different individuals). Additional sampling issues identified included the decision to use random sampling instead of purposeful sampling strategies to select a representative qualitative sample to facilitate data comparisons and the decision of how to analyze and report quantitative results when using a small quantitative sample.

Procedural issues also arose as the researchers attempted to mix and relate their two data sets. For example, some authors described designing the questions asked on the quantitative and qualitative data collection protocols so that they addressed the same issues (Knodel \& Saengtienchai, 2005) or even used identical questions (Miall \& March, 2005b) to facilitate relating the two different sets of findings. Some researchers noted procedural considerations when they transformed qualitative data into quantitative counts. For example, Gomel et al. (1998) described using the same probes in all of their qualitative focus groups to facilitate the transformation of the qualitative results into quantitative values and the analysis of the transformed data. They also discussed the importance of carefully defining the unit of analysis when analyzing transformed data (such as analyzing by focus group, not by individual).

Mixed methods scholars have noted that many mixed methods studies do not sufficiently integrate (or mix) their quantitative and qualitative methods (Greene et al., 1989; O'Cathain et al., 2007). Creswell and Plano Clark (2007) suggest that the researcher pose a mixed methods research question in addition to quantitative and qualitative research questions in order to clarify how the researcher intends to mix the two data types in a mixed methods study and to ensure that the understandings produced by the study are more than simply what would have been learned by separate quantitative and qualitative studies. None of the studies in this sample explicitly stated such a question in 
the article text. As part of our analysis, however, we developed a mixed methods question that we felt captured the authors' implicit intents for mixing methods within each of the studies. The format of these suggested mixed methods questions varied based on the mixed methods design types. For example, we posed the following questions for two studies using triangulation designs: How do the qualitative data illustrate the quantitative statistical results about the older generation's adjustment? (developed for Katz \& Lowenstein, 1999), and To what extent are the quantitative and qualitative results about parents' support roles for adult children with AIDS consistent? (developed for Knodel $\&$ Saengtienchai, 2005). An example of a mixed methods question written for an explanatory design (where quantitative data are used first) is, How do the qualitative themes explain the differences between the ethnic groups? (developed for Javo et al., 2003). For the exploratory study of Richter (1997) that began with a qualitative phase, we suggest the following mixed methods question: How well does the qualitative model of child care decision making generalize to the quantitative sample?

Other procedural issues relate to the logistics of conducting mixed methods research. Miall and March (2005a) raised the issue of increased training demands when they stated in their article that their study required assistants trained in both quantitative and qualitative methodologies. These researchers also made note of the challenge they faced when proposing their study for funding. Although their intent was to use qualitative data to explain quantitative results (calling for an explanatory design), they explained in a footnote that their funding agency mandated that they implement the qualitative phase first, and therefore their study used an exploratory design (Miall \& March, 2005b). This gives at least some evidence that at least one family science study had difficulty convincing an audience as to the merit of a particular mixed methods design.

A final logistical issue that emerged from these studies concerns publishing mixed methods approaches. Although most of the studies reported the quantitative and qualitative components within one article, Javo et al. (2003) chose to report their follow-up qualitative phase in a separate article from the initial quantitative results (Javo, Ronning, \& Heyerdahl, 2004). They referred to the other publication so that the readers could understand the overall mixed approach and context of the qualitative follow-up. Authors also used different strategies for reporting their two sets of results within one published article, such as interweaving the quantitative and qualitative evidence throughout the discussion of each main result in the result section (e.g., Struthers \& Bokemeier, 2000) or reporting each in a separate section because they 
were conducted separately (e.g., Gomel et al., 1998). Strazdins and Broom (2004) discussed their qualitative results as subheadings under the quantitative sections, thereby conveying the apparent quantitative weighting of their study. Miall and March (2005a, 2005b) noted the difficulty of reporting two sets of results within one article by commenting about the need to limit the use of representative quotes for their qualitative results due to page constraints.

\section{Discussion}

This study revealed that family scientists are using mixed methods designs in their research, but this approach is not currently prevalent in the four journals reviewed. Each of the journals, however, had published at least three mixed methods studies in the past decade; thus, mixed methods designs are being successfully conducted and published in the discipline at this time, even if few in number. Among the identified family science studies, we found examples of a variety of mixed methods designs (triangulation, explanatory, and exploratory) and described some of the procedural and logistical challenges faced by family researchers who are applying this approach within their studies.

This study of the use of mixed methods in family science adds to the growing literature discussing disciplinary contexts for conducting mixed methods research (e.g., Greene et al., 1989, evaluation; Creswell, Goodchild, \& Turner, 1996, higher education; Creswell et al., 2004, primary health care; Hanson et al., 2005, counseling psychology). Beyond these previous works, this examination added the discipline of family science to this discussion, used a more recent design typology (i.e., Creswell \& Plano Clark, 2007), and placed an emphasis on the broad types of procedural issues raised within reported studies.

Consistent with other disciplines, we found that the family science authors did not use a common language to identify mixed methods within their research. This lack of consensus on mixed methods terminology has been previously documented in family science (Hendrickson Christensen \& Dahl, 1997; Mangen, 1995; Rank, 1988, 1996), in other disciplines (Plano Clark, 2005), and in the literature in general (Tashakkori \& Teddlie, 2003). The use of important mixed methods terminology, such as timing and weighting, indicates researchers' awareness of this approach and the important decisions that are made when designing a mixed methods study. As family science researchers become more familiar with mixed methods designs, we expect this terminology will become commonplace in reports of mixed methods studies. 
With few exceptions, the examined studies collected data through surveys and interviews. It is possible that this is a product of our search strategies (which identified studies that reported using a "survey" and "interview"). Even so, many studies reported only rudimentary analytic techniques, such as reporting percentages and means for the quantitative data and simply identifying quotations from the qualitative data; few examples conducted sophisticated analyses (such as multiple regression quantitative analysis or axial and selective coding in qualitative grounded theory analysis). This finding agrees with similar results from other disciplines (e.g., Plano Clark, 2005) and may in part indicate the inherent difficulty of mixing two sophisticated approaches. However, this finding may also be indicative of researchers' lack of experience in using one or both methods. Perhaps as more researchers use mixed methods or work in collaborative teams on mixed methods studies, the procedures will show greater sophistication.

This review found that the mixed methods design typology of Creswell and Plano Clark (2007) can be successfully used to describe the types of mixed methods designs currently being conducted by family scholars. However, most of the articles' authors did not perceptibly report their studies as having used a mixed methods design. Having a well-designed plan or logic from which to base a study is an essential element of quality research (Creswell, 2005; Yin, 2003). We believe that the methodological rigor of these studies could have been conveyed more strongly if the researchers had reported them using the framework of a particular mixed methods design best suited to address their research questions. In particular, having a clear design in mind would encourage the authors to make stronger arguments for why the design type was selected to address the study's purpose and to carefully consider what more could be learned by explicitly mixing the two data sets.

Unlike other disciplines that have been found to use predominately concurrent approaches (Hanson, et al., 2005; Plano Clark, 2005), our review found that both concurrent and sequential approaches are being reported in family science. It is surprising that no studies were identified as using an embedded design. It is unclear if this is an artifact of our search strategies or if this design is currently not found in family research. Examinations of other disciplines such as the health sciences have noted that embedded designs are particularly useful when researchers want to enhance an experimental study by including a qualitative component in addition to testing an intervention (Creswell et al., in press; Sandelowski, 1996). This result may therefore indicate a lack of experimental studies in general in family science research. Family researchers who do conduct experimental or correlational studies should 
consider the advantages of embedding a qualitative component within their designs and whether such a design may help them better address their overall research aims.

The logistical issues associated with conducting a mixed methods study remain among the unresolved issues of mixed methods research (Tashakkori \& Teddlie, 2003), and little work has examined the presence of these issues in reported mixed methods studies. From this limited sample, issues emerged related to funding, specifying the study's intent, selecting samples, training demands, and publishing challenges. Family researchers who consider using a mixed methods design should familiarize themselves with the different stances and options available for these and many other important issues with implementing mixed methods designs.

We recognize various shortcomings in our study. In our systematic review of articles, we acknowledge that these selections do not comprise an exhaustive list of mixed methods research studies within the family science discipline, nor were they intended to be. We realize that the self-imposed restrictions of journal source, time period, and search terminology could not adequately capture the entirety of mixed method research, particularly due to the selection of all U.S.-based journals. We also acknowledge that the article authors did not explicitly use a mixed methods design framework, and therefore, our classifications of the studies are based on our subjective judgments of the studies' procedures as they were described in the articles. Future research could include the perspectives of family science researchers using mixed methods approaches.

Even with these limitations in mind, this review presents a current snapshot of how mixed methods approaches are being implemented within family science research. In addition, it provides family scholars with models of mixed methods studies from the field that have been successfully published in a mainstream family science journal. Based on our findings, we conclude with the following recommendations for family scientists considering using mixed methods research.

\section{Recommendations}

1. We urge family scholars to adopt common terminology to identify and report the important features of their mixed methods designs. Authors should acknowledge their use of a mixed methods approach that combines quantitative and qualitative methods and, when possible, utilize mixed methods language in the title, abstract, and methods section. A mixed methods design should be identified and important features of the design should be explicitly discussed so that the reader has a clear understanding of how the design was im- 
plemented. Researchers wanting more information about mixed methods terminology should examine the glossary in the Handbook of Mixed Methods in Social and Behavioral Research (Tashakkori \& Teddlie, 2003).

2. Family scholars considering using mixed methods should first develop a solid understanding of both quantitative and qualitative research methods and methodology. Strong mixed methods studies are built from rigorous quantitative and qualitative components, and researchers need to implement the components well before considering how to mix the two. In particular, researchers with strong quantitative training need to develop an understanding of qualitative research including its philosophical underpinnings and basic data analysis procedures (coding and thematic development), as well as the application of specific approaches such as grounded theory, case study, and narrative research. Qualitative methods should entail more than identifying quotations.

3. We recommend that researchers include a mixed methods research question, such as those suggested in this article, to make the intention of their mixing explicit. A rigorous mixed methods study results in an understanding that goes beyond simply adding together separate quantitative and qualitative studies. Unfortunately, many researchers devote little attention to mixing the two components because they may be unsure of how to accomplish it. Therefore, researchers need to consider how the two databases will relate to each other and design procedures to facilitate the mixing. These procedures can be guided by a mixed methods question that clearly states how the researcher intends to relate the results of the two data sets. In addition, the results to the mixed methods question can be reported in addition to the quantitative and qualitative results.

4. As family researchers conduct mixed methods research, they should pay careful attention to the logistical challenges that develop during the implementation of their studies and report these in their publications. In this way, family researchers, as well as others interested in mixed methods research, can better learn to anticipate and address such issues. Mixed methods studies are complex, and the better researchers are aware of the challenges of this design for investigating family issues, the more likely and the better they will be able to use them to meaningfully address important research questions that will advance the field.

Undoubtedly, mixed methods research has been conducted within the family science discipline in the past decade. Mixed methods designs are a natural fit for the different theoretical perspectives and the types of dynamic and contextual research questions addressed in the field. Family scholars should develop an increased awareness and appreciation of mixed methods designs as introduced in this article, as this methodological tradition has great potential for addressing many of the issues and phenomena of interest to family science. 


\section{References}

Brewer, J., \& Hunter, J. (1989). Multimethod research: A synthesis of styles. Newbury Park, CA: Sage.

Burgess, E. W. (1927). Statistics and case studies as methods of sociological research. Sociology and Social Research, 12, 103-120.

Campbell, C. L., \& Demi, A. S. (2000). Adult children of fathers missing in action (MIA): An examination of emotional distress, grief, and family hardiness. Family Relations, 49(3), 267-276.

Carr, D. (2005). The psychological consequences of midlife men's social comparisons with their young adult sons. Journal of Marriage and Family, 67(1), 240-250.

Coleman, M. (Ed.). (1995). Journal of Marriage and the Family, 57(4).

Creswell, J. W. (1999). Mixed-method research: Introduction and application. In G. J. Cizek (Ed.), Handbook of educational policy (pp. 455-472). San Diego, CA: Academic Press.

Creswell, J. W. (2005). Educational research: Planning, conducting, and evaluating quantitative and qualitative research (2nd ed.). Upper Saddle River, NJ: Pearson Education.

Creswell, J. W., Fetters, M. D., \& Ivankova, N. V. (2004). Designing a mixed methods study in primary care. Annals of Family Medicine, 2(1), 7-12.

Creswell, J. W., Fetters, M. D., Plano Clark, V. L., \& Morales, A. (in press). Nesting qualitative data in health sciences intervention trials: A mixed methods application. In S. Andrew \& L. Halcomb (Eds.), Mixed methods research for nursing and the health sciences. Oxford, UK: Blackwell.

Creswell, J. W., Goodchild, L. F., \& Turner, P. P. (1996). Integrated qualitative and quantitative research: Epistemology, history, and designs. In J. C. Smart (Ed.), Higher education: Handbook of theory and research (Vol. 11, pp. 90-136). New York: Agathon.

Creswell, J. W., \& Plano Clark, V. L. (2007). Designing and conducting mixed methods research. Thousand Oaks, CA: Sage.

Creswell, J. W., Plano Clark, V. L., Gutmann, M. L., \& Hanson, W. E. (2003). Advanced mixed methods research designs. In A. Tashakkori \& C. Teddlie (Eds.), Handbook of mixed methods in social and behavioral research (pp. 209-240). Thousand Oaks, CA: Sage.

Creswell, J. W., Tashakkori, A., Jensen, K. D., \& Shapley, K. L. (2003). Teaching mixed methods research: Practices, dilemmas, and challenges. In A. Tashakkori \& C. Teddlie (Eds.), Handbook of mixed methods in social and behavioral research (pp. 619-637). Thousand Oaks, CA: Sage.

Dalla, R. L., \& Gamble, W. C. (1997). Exploring factors related to parenting competence among Navajo teenage mothers: Dual techniques of inquiry. Family Relations, 46(2), 113-121.

Gibson-Davis, C. M., Edin, K., \& McLanahan, S. (2005). High hopes but even higher expectations: The retreat from marriage among low-income couples. Journal of Marriage and Family, 67(5), 1301-1312.

Gomel, J. N., Tinsley, B. J., Parke, R. D., \& Clark, K. M. (1998). The effects of economic hardship on family relationships among African American, Latino, and Euro-American families. Journal of Family Issues, 19(4), 436-467.

Greene, J. C. (2005). Synthesis: A reprise on mixing methods. In T. S. Weisner (Ed.), Discovering successful pathways in children's development: Mixed methods in the study of childhood and family life (pp. 405-419). Chicago: University of Chicago Press.

Greene, J. C., \& Caracelli, V. J. (Eds.). (1997). Advances in mixed-method evaluation: The challenges and benefits of integrating diverse paradigms. In New directions for evaluation (Vol. 74). San Francisco: Jossey-Bass. 
Greene, J. C., Caracelli, V. J., \& Graham, W. F. (1989). Toward a conceptual framework for mixed- method evaluation designs. Educational Evaluation and Policy Analysis, 11(3), 255-274.

Greenstein, T. N. (2006). Methods of family research (2nd ed.). Thousand Oaks, CA: Sage.

Handel, G. (1996). Family worlds and qualitative family research: Emergence and prospects of whole-family methodology. In M. B. Sussman \& J. F. Gilgun (Eds.), The methods and methodologies of qualitative family research (pp. 335-348). Binghamton, NY: Haworth.

Hanson, W. E., Creswell, J. W., Plano Clark, V. L., Petska, K. P., \& Creswell, J. D. (2005). Mixed methods research designs in counseling psychology. Journal of Counseling Psychology, 52(2), 224-235.

Hendrickson Christensen, D., \& Dahl, C. M. (1997). Rethinking research dichotomies. Family and Consumer Sciences Research Journal, 25(3), 269-285.

Javo, C., Alapack, R., Heyerdahl, S., \& Ronning, J. A. (2003). Parental values and ethnic identity in indigenous Sami families: A qualitative study. Family Process, 42(1), 151-164.

Javo, C., Ronning, J. A., \& Heyerdahl, S. (2004). Child-rearing in an indigenous Sami population in Norway: A cross-cultural comparison of parental attitudes and expectations. Scandinavian Journal of Psychology, 45(1), 67-78.

Jick, T. D. (1979). Mixing qualitative and quantitative methods: Triangulation in action. Administrative Science Quarterly, 24, 602-611.

Katz, R., \& Lowenstein, A. (1999). Adjustment of older Soviet immigrant parents and their adult children residing in shared households: An intergenerational comparison. Family Relations, 48(1), 43-50.

Knodel, J., \& Saengtienchai, C. (2005). Older-aged parents: The final safety net for adult sons and daughters with AIDS in Thailand. Journal of Family Issues, 26(5), 665-698.

Lavee, Y., Ben-David, A., \& Azaiza, F. (1997). Israeli and Palestinian families in the peace process: Sources of stress and response patterns. Family Process, 36(3), 247-263.

Mangen, D. J. (1995). Methods and analysis of family data. In R. Blieszner \& V. Hilkevitch Bedfor (Eds.), Handbook of aging and the family (pp. 148-177). Westport, CT: Greenwood.

Marshall, T., \& Solomon, P. (2004). Provider contact with families of adults with severe mental illness: Taking a closer look. Family Process, 43(2), 209-216.

Mason, M. A., Harrison-Jay, S., Svare, G. M., \& Wolfinger, N. H. (2002). Stepparents: De facto parents or legal strangers? Journal of Family Issues, 23(4), 507-522.

McGraw, L. A., Zvonkovic, A. M., \& Walker, A. J. (2000). Studying postmodern families: A feminist analysis of ethical tensions in work and family research. Journal of Marriage and Family, 62(1), 68-77.

Mertens, D. M. (2003). Mixed methods and the politics of human research: The transformative- emancipatory perspective. In A. Tashakkori \& C. Teddlie (Eds.), Handbook of mixed methods in social and behavioral research (pp. 135-164). Thousand Oaks, CA: Sage.

Miall, C. E., \& March, K. (2005a). Community attitudes toward birth fathers' motives for adoption placement and single parenting. Family Relations, 54(4), 535-546.

Miall, C. E., \& March, K. (2005b). Open adoption as a family form. Journal of Family Issues, 26(3), 380-410.

Miles, M. B., \& Huberman, A. M. (1994). Qualitative data analysis: An expanded sourcebook (2nd ed.). Thousand Oaks, CA: Sage.

Morgan, D. L. (1998). Practical strategies for combining qualitative and quantitative methods: Applications to health research. Qualitative Health Research, 8(3), 362-376.

Morse, J. M. (1991). Approaches to qualitative-quantitative methodological triangulation. Nursing Research, 40, 120-123.

National Council on Family Relations Annual Conference. (2006). 2006 NSFR call for papers. Retrieved January 15, 2006, from http://www.ncfr.org/pdf/Call_for_Proposals.pdf 
O'Brien, M. (2005). Studying individual and family development: Linking theory and research. Journal of Marriage and Family, 67(4), 880-890.

O'Cathain, A., Murphy, E., \& Nicholl, J. (2007). Integration and publications as indicators of "yield" from mixed methods studies. Journal of Mixed Methods Research, 1(2), 147-163.

Perlesz, A. L., \& Lindsay, J. (2003). Methodological triangulation in researching families: Making sense of dissonant data. International Journal of Social Research Methodology, 6(1), $25-40$

Plano Clark, V. L. (2005). Cross-disciplinary analysis of the use of mixed methods in physics education research, counseling psychology, and primary care. (Doctoral dissertation, University of Nebraska-Lincoln, 2005). Dissertation Abstracts International, 66, 02A.

Punch, K. F. (1998). Introduction to social research: Quantitative and qualitative approaches. London: Sage.

Rank, M. R. (1988, November). The blending of quantitative and qualitative data in family research. Paper presented at the National Council of Family Relations Pre-Conference Workshop on Theory Construction and Research Methodology, Philadelphia, PA.

Rank, M. R. (1996). The blending of qualitative and quantitative methods in understanding childbearing among welfare recipients. In J. F. Gilgun, K. J. Daly, \& G. Handel (Eds.), Qualitative methods in family research (pp. 281-300). Newbury Park, CA: Sage.

Richter, K. (1997). Child care choice in urban Thailand: Qualitative and quantitative evidence of the decision-making process. Journal of Family Issues, 18(2), 174-204.

Sale, J. E., Lohfeld, L. H., \& Brazil, K. (2002). Revisiting the quantitative-qualitative debate: Implications for mixed-methods research. Quality and Quantity, 36, 43-53.

Sandelowski, M. (1996). Using qualitative methods in intervention studies. Research in Nursing and Health, 19(4), 359-364.

Sandelowski, M. (2003). Tables or tableaux? The challenges of writing and reading mixed methods studies. In A. Tashakkori \& C. Teddlie (Eds.), Handbook of mixed methods in social and behavioral research (pp. 321-350). Thousand Oaks, CA: Sage.

Shulha, L. M., \& Wilson, R. J. (2003). Collaborative mixed methods research. In A. Tashakkori \& C. Teddlie (Eds.), Handbook of mixed methods in social and behavioral research (pp. 639-669). Thousand Oaks, CA: Sage.

Smith, J. K., \& Heshusius, L. (1986). Closing down the conversation: The end of the quantitative-qualitative debate among educational inquirers. Educational Researcher, 15(1), 4-12.

Strazdins, L., \& Broom, D. H. (2004). Acts of love (and work): Gender imbalance in emotional work and women's psychological distress. Journal of Family Issues, 25(3), 356-378.

Struthers, C. B., \& Bokemeier, J. L. (2000). Myths and realities of raising children and creating family life in a rural county. Journal of Family Issues, 21(1), 17-46.

Tashakkori, A., \& Teddlie, C. (1998). Mixed methodology: Combining qualitative and quantitative approaches. Thousand Oaks, CA: Sage.

Tashakkori, A., \& Teddlie, C. (Eds.). (2003). Handbook of mixed methods in social and behavioral research. Thousand Oaks, CA: Sage.

Walker, A. J. (Ed.). (2005). Theoretical and methodological issues in studying families [Special issue]. Journal of Marriage and Family, 67(4).

Weigel-Garrey, C. J., Cook, C. C., \& Brotherson, M. J. (1998). Children and privacy: Choice, control, and access in home environments. Journal of Family Issues, 19(1), 43-64.

Weine, S., Knafl, K., Feetham, S., Kulauzovic, Y., Klebic, A., Sclove, S., et al. (2005). A mixed methods study of refugee families engaging in multiple-family groups. Family Relations, 54(4), 558-568.

Yin, R. K. (2003). Case study research: Design and methods (3rd ed.). Thousand Oaks, CA: Sage. 